\title{
Knowledge, Attitude and Practice of medical students towards COVID19 in Sudan, 2020: A cross sectional study among 19 universities
}

Radi Tofaha Alhusseini ( $\square$ radi.tuffaha1995@gmail.com )

Alzaiem alazhari university https://orcid.org/0000-0002-7778-5331

Mohammed Alfatih Abdoalgadir

Alzaiem alazhari university

Khabab Abbasher Hussien Mohamed Ahmed ( $\square$ Khabab9722@gmail.com )

University of Khartoum https://orcid.org/0000-0003-4608-5321

Rua Isameldin Bakhiet Mohamed

University of Khartoum

Monzer Omer Ahmed Abdalla

University of Gezira

Khadija ala Abdalmaqsud muhmmed

Omdurman Islamic University

Osama Mohammed Nowar Taha

Omdurman Islamic University

Yaman Shurki Adel Husni Yousef

Elrazi University

Rawan Raad Hassan Alrufai

Sudan University of Science and Technology

AHMED EMADALDEEN AHMED MOHAMMED ALAMIN

West kordofan University

Muzamil Musa Mohamed Musa

, Al Neelain University

Saida abdallah mohammed taha abdallah

Ahfad university for women

MOHAMMED MAHMMOUD FADEL ALLAH MOHAMMED

University Of Bakht Alruda

Basaier Mohammed Alamaldeen Kharif

Dalanj University

Areej Imad Aldeen Mohamed Idris

Sudan international University

Sara Mohamed Abdalla Idris 
Ibn Sina University

Mohamed Ahmed Abugibba Mohamed

University of Medical Sciences and Technology

\section{Malaz Salah Osman Gurashi}

University of science and technology

\section{Mohammed Alfateh omer Mohammed}

National university

\section{Ahmed Bukhari Mohamed Ahmed}

Shendi University

\section{Isra Mohamed Hassan Nasr}

Karary University

\section{Abdlrhman saeed mohammed saeed}

Nile village university

\section{Ahmed ElSayed}

Alzaiem Alazhari university

\section{Research Article}

Keywords: knowledge, attitude and practice, COVID-19, Medical students

Posted Date: May 3rd, 2021

DOI: https://doi.org/10.21203/rs.3.rs-490884/v1

License: () (1) This work is licensed under a Creative Commons Attribution 4.0 International License.

Read Full License 


\section{Abstract}

Introduction: Since December 2019, an outbreak of severe respiratory infection (COVID-19) emerged in the city of Wuhan in China. It quickly spread around the world and is now a pandemic of epic proportions. Medical students are the future generation of doctors who will have to face this and any future similar catastrophe. The knowledge, awareness and practice of medical students toward Covid19 pandemic is of most importance as it demonstrates their preparedness to deal with this pandemic.

Objective: To assess the knowledge, awareness and practice of medical students in 19 universities in Sudan about COVID 19.

Methodology: This is a cross-sectional study done in 19 universities which have medical schools in Sudan. Data from at least 100 medical students from each university was included in the study. Data was collected using an online questionnaire in April 2020.

Results: 2603 medical students from 19 universities were included. Overall good knowledge and practice were demonstrated by the medical students $(88.9 \%)$ and (78.6\%), respectively. Respondents answered that the most common clinical symptoms of COVID-19 were fever (51.9\%), dry cough (40.5\%). The main combination of clinical symptoms was dry cough, fatigue and fever in (27.7\%), and the first initial symptom was headache (48.4\%.).(60.2\%) wear medical masks, $(94.9 \%)$ said that avoiding crowded places protects against the spread of Covid19. (50.9\%) have confidence that Sudan can win the battle against the COVID-19 with (48.6\%) amongst males and (52.2\%) amongst females. $69.0 \%$ agreed that COVID-19 will finally be successfully controlled.

Conclusion: This study showed that medical students in Sudan demonstrated excellent Knowledge and good practice toward Covid19.

Recommendations: Although the results were very positive, further education and awareness should be carried out to increase the preparedness of medical students towards such pandemics and public health modules should also focus more on the importance of the knowledge of newly emerging diseases and the practices toward them.

\section{Introduction}

Medical students have become increasingly visible working side by side with other health care providers giving support and spreading awareness in their communities to help raise the standards of living for their surrounding communities so their knowledge and awareness and practice are an important aspect to achieve optimum health and people look up to them as they are the doctors of the future.

Since December 2019, an outbreak of severe respiratory infection emerged in the city of Wuhan in China $[1,2]$. The disease was linked to the Wuhan's Seafood Market, which deals in fish and many other animal species like bats and snakes[3] On the 7th of January 2020, the Chinese Centre for Disease Control and 
Prevention (CCDC) isolated the causative agent from throat swab samples and the name Severe Acute Respiratory Syndrome Coronavirus 2 (SARS-CoV-2) was given to this virus. The World Health Organization (WHO) then renamed it as Corona virus disease-19 (COVID-19) [4].

Coronaviruses are a large family of enveloped RNA viruses found in a broad range of animals including camels, cattle, cats, and bats. In relatively rare events, vectors can transmit coronaviruses to humans with continued circulation resulting in human-to-human exposure.

COVID-2019 is the third coronavirus emerging in the human population in the past two decades, having been preceded by the SARS-CoV outbreak in 2002 and the MERS-CoV outbreak in 2012. All of these viruses originated in bats [5]. Initially, 2019-nCov patients were shown to have some link to the Wuhan market suggesting animal-to-person transmission. However, an increasing number of cases appear to have resulted from human-to-human contact as growing numbers of patients were shown not to be exposed to animal markets [6]. This spread has now resulted in a worldwide pandemic which has put global health institutions on alert. At present, no antiviral medication or vaccine is available for COVID 19 infection and infected patients are managed with supportive care [6].

The symptoms of COVID-19 infection appear after an incubation period of approximately 5.2 days ( 1 to 14 days) [7]. The period from the onset of COVID-19 symptoms to death ranges from 6 to 41 days with a median of 14 days [8]. This period is dependent on the age of the patient and status of the patient's immune system. It was shorter among patients more than 70-years old compared with those under the age of 70 [8]. The most common symptoms at onset of COVID-19 are fever, cough, and fatigue, while other symptoms include sputum production, headache, hemoptysis, diarrhea, dyspnea, and lymphopenia $[8,9,10,11]$. Clinically the disease presents as an acute respiratory distress syndrome and acute cardiac injury, leading to death [10]. In some cases CT scanning shows multiple peripheral ground-glass opacities in subpleural regions of both lungs [12].

It is important to note that there are similarities in the symptoms between COVID-19 and earlier beta coronavirus such as fever, dry cough, dyspnea, and bilateral ground-glass opacities on chest CT scans [8]. However, COVID-19 showed some unique clinical features that include the targeting of the lower airway as evident by upper respiratory tract symptoms like rhinorrhea, sneezing, and sore throat $[13,14]$. In addition, based on results from chest radiographs upon admission, some of the cases show an infiltrate in the upper lobe of the lung that is associated with increasing dyspnea with hypoxemia [15]. Importantly, whereas patients infected with COVID-19 developed gastrointestinal (GI) symptoms like diarrhea, a low percentage of MERS-CoV or SARS-CoV patients experienced similar GI distress. Therefore, it is important to test fecal and urine samples to exclude a potential alternative route of transmission, specifically through health care workers and patients $[13,14]$.

Comorbidities were found in almost $50 \%$ of patients with COVID-19. Hypertension is the most commonly recognized one, followed by diabetes mellitus and heart diseases [16]. Infection with COVID-19 has been reported in all ages, even children, with $54.3 \%$ of those infected being males [17]. 
In comparison between the patients that recovered from the infection and those who died, the latter had more abnormalities associated with their coagulation profile manifesting as a longer prothrombin time, shorter activated partial thromboplastin time (APTT) and lower platelet counts. Also, D-dimer elevation was commonly found in the severely ill COVID-19 patients [18]. It may be that inflammatory injury by COVID-19 infection can lead to coagulopathy, platelet aggregation, and thrombosis, with an increased platelet consumption and destruction [19]. On the other hand, an elevation in aspartate aminotransferase (AST) was detected in (62\%) of cases admitted in the ICU in comparison with (25\%) of patients who did not need admission in the ICU [20].

From the above it seems the world now has a viral pandemic on its hands which has new features and for which no treatment is currently available. For all intents and purposes this viral infection seems set to be around for many years to come with the current pandemic expected to last till 2021 [21]. Therefore, knowledge and awareness and practice of COVID19 infection among medical students is important because they will be in the front line against this virus in the future.

In this study we plan to study the knowledge, attitude and practice of medical students in 19 universities in Sudan about COVID 19.

\section{Literature Review}

As the COVID 19 pandemic is a new pandemic, there are few studies looking at knowledge awareness and practice about COVID 19 in medical students. A cross-sectional study conducted in Jordan, to assess the knowledge, practice and attitude (KAP) of university students from medical and non-medical colleges in Jordan using a structured questionnaire involved a total number of 592 students. The study found that overall good knowledge about the symptoms of COVID-19 was observed in more than $90 \%$ of the students. In attitude and practice $99.7 \%$ of the participants agreed that hand washing is necessary for prevention of infection whereas $68.4 \%$ believed that mask wearing would prevent the infection. $20.6 \%$ and $19.2 \%$ students believed antibiotics and smoking to be a protective measure against the infection respectively. Also, 96.8\% avoid hand shaking, $98.8 \%$ wash their hands and $93.3 \%$ use alcoholic rub, 95.8\% cough or sneeze in a tissue and dispose of it in a waste bin. Social media was the commonest source (34\%) followed by the WHO (19.9\%), TV (17.6\%), internet (13\%), Ministry of Health (10.1\%) and friends (5.4\%). The study concluded that there is a need for more detailed and directed measures and awareness campaigns to improve the knowledge, attitude and practice in some critical aspects to contain the virus [22]. A somewhat related community-based study looked into COVID KAP amongst Chinese residents, and was conducted during the rapid rise period of the outbreak of COVID19. An online KAP questionnaire consisting of 12 questions to assess knowledge and 2 questions for attitude and 2 questions for practice was used on a sample consisting of 6910 participants. This study concluded that the participating Chinese residents were of a relatively high socioeconomic status, in particular women, had good knowledge, optimistic attitudes, and appropriate practices (90\%) towards COVID-19 during the rapid rise 
period of the COVID-19 outbreak. In addition, good COVID-19 knowledge is associated with optimistic attitudes and appropriate practices (90,8\%) towards COVID-19 [23]

A cross-sectional study related to another coronavirus (MERS) was conducted in Saudi Arabia evaluating knowledge of medical students in the clinical aspects of MERS. The data was collected using an online questionnaire. using a researcher-administered and a self-reported questionnaire that had been previously validated. 136 students participated and showed good awareness regarding the clinical aspects of MERS, such as etiology, diagnosis, management, and prevention Approximately $92 \%$ of the students knew that there was no vaccination available, and $97 \%$ of them were knowledgeable about the mode of transmission .However, $(76 \%)$ of the students were not aware of the mortality rate. Also the study showed that there was gender difference, as more male students did not know the correct incubation period of the virus and the possible asymptomatic presentation of the disease, and the difference between the genders was statistically significant with $p$ values of 00.01 and 0.004 , respectively however male students were more aware of the diagnostic test than female students, which was statistically significant with a $p$ value of 0.04 . Social media was the most common source of obtaining information (55\%). However, male students were more aware of the diagnostic tests for MERS than their female counterparts and the study concluded that medical students were knowledgeable about the clinical aspects of MERS but were lacking background awareness in the basic sciences [24].

\section{Materials And Methods}

This study is a cross-sectional study done in 19 universities which have medical schools in Sudan out of a total of 24 medical schools only 19 medical schools met the criteria to be included in the study (which was to have at least 100 medical students from each university randomly to be included in the study. These medical schools were chosen according to those that were willing to participate (see Fig. 1).

The target participants were medical students in these targeted medical schools who consented to participate in the study. They were approached by a member of the study team from their own university asking them if they would consent to participate and if the answer was positive availing them of the link to the study on a Google form. This approach was predominantly done by using social media (Facebook and WhatsApp) which is very widely used amongst students in all universities in Sudan. This approach was complemented by telephone calls to stress importance of the research in some instances and repeat of the messages on the social media platforms if the response rate slowed down and to ensure that only one response per participant Respondents were required to sign in to fill the google form using their google account via their G-mail address.

This approach was more successful than originally anticipated and in the period from $7 / 4 / 2020$ to $18 / 4 / 2020$ all the required responses were collected.

The study instrument (see appendix 1) was an online questionnaire delivered by Google forms and consisted of two parts: 
Part one: Demographic data which had 6 variables (age, gender, academic year, university, marital status and nationality).

Part two: Following the guidelines for clinical and community management of COVID-19 by the National Health Commission of the People's Republic of China [25.26], a COVID-19 knowledge questionnaire was developed by the authors and to it were added questions about the attitude and practice towards COVID19 among medical students. This part had 23 questions regarding knowledge of COVID-19. A correct answer was assigned 1 point and an incorrect/unknown answer was assigned 0 points. making the knowledge score range from 0 to 23, with a higher score denoting a better knowledge of COVID-19. Attitudes towards COVID-19 were measured by 2 questions and respondents' practice was assessed by 10 questions.

This questionnaire was initially self-tested by the authors before implementation and a pilot study was done with 40 participants.

\section{Ethical consideration}

Ethical approval was obtained from the ethical committee of the Alzaiem Alazhari University and the Federal Ministry of Health of the Republic of Sudan. Participants had to answer a yes-no question to confirm their willingness to participate voluntarily. After confirmation of the question, the participant was directed to complete the online questionnaire.

All the costs of doing this study were borne by the authors who had no conflict of interest

\subsection{Statistical analysis:}

Statistical analysis was performed using the Statistical Package for Social Science (SPSS, Version 25). A $\mathrm{p}$-value of less than 0.05 was used to determine the level of significance. Results were expressed as tables and figures.

\section{Results}

2603 medical students from 19 universities (Table 1) responded to the survey. As expected, $91.1 \%$ were between 18 to 24 years of age (Fig. 2) with $90.4 \%$ of them being between the first and fifth medical year (Fig. 3)

The respondents were predominantly Sudanese (93.4\%) and (93.2\%) were single. They were evenly spread in the level they were in in medical school from year 1 to year 5 with those in year 6 being less in numbers (Fig. 4), this latter fact was because 12 out of the 19 medical schools had a 5 -year program only. Among them, a total of 402 (15.4\%), 512 (19.7\%), 487 (18.7\%), 508 (19.5\%), 445 (17.1\%), 249 (9.6\%) students were from first, second, third and fourth year respectively. 
Table 1

Distribution of respondents by university

\begin{tabular}{|ll|}
\hline University & Frequency \\
\hline Ahfad University for Women & 110 \\
\hline AlNeelain University & 331 \\
\hline Alzaiem Alazhari University & 104 \\
\hline Dalanj University & 105 \\
\hline El Razi university & 113 \\
\hline Ibn Sina University & 106 \\
\hline Karary University & 177 \\
\hline Khartoum University & 206 \\
\hline National University & 103 \\
\hline Nile valley university & 126 \\
\hline Omdurman Islamic university & 213 \\
\hline Shendi University & 105 \\
\hline Sudan international university & 114 \\
\hline Sudan University of Science and Technology & 129 \\
\hline University of bakht alruda college of medicine & 110 \\
\hline University of Gezira & 109 \\
\hline University of medical science and technology & 101 \\
\hline University of science and technology & 103 \\
\hline West Kordufan University & 138 \\
\hline Total & 2603 \\
\hline
\end{tabular}

Participants responded that the most common clinical symptoms of COVID 19 were fever (51.9\%), dry cough (40.5\%), the main combination of clinical symptoms was dry cough, fatigue and fever in $(27.7 \%)$ and the first initial symptom identified as headache (48.4\%.). We found an interesting finding is that most of the students in level 2 identified the first initial symptom is headache followed by level 3,4,1,5 and 6 respectively which was significantly different $(p<0,0016)$ Note level 6 students are less in number as mentioned above.

(93.9\%) of them identified that respiratory droplets are the main route of spread of covid19 and it was highly associated with the level of the medical student with a P value less than $(<.0001)$ 
In the practice part (60.2\%) wear medical masks, (94.9\%) said that avoiding crowded places protects against the spread of Covid19, (86.2\%) identified that asymptomatic persons, with no fever cannot spread the virus. (50.1\%) identified that eating or contacting wild, infected animals can spread Covid19. (72.6\%) identified that wearing mask during work in the hospital protects against the spread of the virus. $(97.1 \%)$ said that people who have contact with someone infected with the COVID-19 virus should be immediately isolated for an observation period of 14 days. (79.6\%) said the new greeting for the coronavirus is by elbow. $(9.2 \%)$ by hands and $(11.3 \%)$ said I do not know how is the greeting during covid19 pandemic. (83.4\%) think that Corona-virus can spread in hot tropical climate. (53.7\%) think that Coronavirus COVID-19 can spread by Air. (11.4\%) think that smoking can have a protective effect against (COVID) 19. (60.4\%) answered that the most sensitive test for corona-virus is RT-PCR and $27 \%$ that the most accurate sample to test for corona-virus is broncho-alveolar lavage. $11.1 \%$ answered that the mortality rate for covid19 is $1-2 \%$. Medical students answered that they get their information about Covid-19 from social media (74.7\%), news and TV (60.7\%), WHO updates (61.4\%), medical journals $(29.3 \%)$ and ministry of health updates (11\%.2). (50.9\%) have confidence that Sudan can win the battle against the COVID-19. (69.0\%) agreed that COVID-19 will finally be successfully controlled whilst $14.2 \%$ disagreed and $16.8 \%$ did not know

A total of $(72.2 \%)$ do not go to crowded places most of them were females $(78.1 \%)$. Females were also more likely to wear masks when leaving home (58.9\%) with a P value $=<.0001$ (significant).

We found a positive association between going to crowded places and age, with the age group 24$25 y e a r s 75,5 \%$ of them not going to crowed places followed by (18-20) age groups $(75.2 \%)$.

Regarding the use of hand sanitizer, (38.5\%) said that they always use hand sanitizer after touching foreign surfaces outside their house, $(26.4 \%)$ answered usually, $(5.9 \%)$ sometimes and $(9.3)$ answered never. (See Table 2)

Table (2) Use of hand sanitizer by gender 


\begin{tabular}{|c|c|c|c|c|c|}
\hline \multicolumn{6}{|c|}{ the use of hand sanitizer with gender } \\
\hline & & & \multicolumn{2}{|l|}{ Gender } & \multirow[t]{2}{*}{ Total } \\
\hline & & & Female & Male & \\
\hline \multirow[t]{8}{*}{ Do you use hand sanitizer? } & \multirow[t]{2}{*}{ Always } & Count & 667 & 334 & 1001 \\
\hline & & $\%$ & $40.0 \%$ & $35.6 \%$ & $38.5 \%$ \\
\hline & \multirow[t]{2}{*}{ Usually } & Count & 424 & 262 & 686 \\
\hline & & $\%$ & $25.5 \%$ & $28.0 \%$ & $26.4 \%$ \\
\hline & \multirow[t]{2}{*}{ Sometime } & Count & 441 & 232 & 673 \\
\hline & & $\%$ & $26.5 \%$ & $24.8 \%$ & $25.9 \%$ \\
\hline & \multirow[t]{2}{*}{ Never } & Count & 134 & 109 & 243 \\
\hline & & $\%$ & $8.0 \%$ & $11.6 \%$ & $9.3 \%$ \\
\hline \multirow{2}{*}{\multicolumn{2}{|c|}{ Total }} & Count & 1666 & 937 & 2603 \\
\hline & & $\%$ & $100.0 \%$ & $100.0 \%$ & $100.0 \%$ \\
\hline $\mathrm{P}$ value $<.004$ (significant) & & & & & \\
\hline
\end{tabular}

(93.1\%) 2424 said that they wash their hands with soap first thing when they get back home with females (95.0\%) slightly better being $t$. Using tissue papers when sneezing or coughing was always, usually, sometime and never, in (42.8\%), (29.9\%), (20.9\%) and (6.5\%) respectively, with females being significantly better ( $P$ value $<.0001) .(43,1 \%)$ of females do not shake hands during this covid19 pandemic and when asked about frequency of hand shaking it was less among females with most of them answering sometime $(54,1 \%)$ which was significantly different from males with $a(p<0,000)$. $(59.3 \%)$ of medical students said that they still shake hands with people after the Covid19 pandemic, most of them were males $(63.5 \%)$ with a $p$ value of $<.001$ (significantly different). $(72.6 \%)$ of medical students said that they still hug people and only (68.9\%) said that they take off their shoes once they get home.

Table (3): the overall knowledge and practice were measured using the following criteria 


\section{Knowledge}

The main clinical symptoms of (COVID-19) are

Most common symptom of (covid19)?

What symptoms are uncommon in COVID-19 patients?

First initial symptom of COVID19?

Which COVID-2019 cases are most likely to develop to severe cases?

Eating or contacting wild animals would result in the infection by the COVID-19 virus?

Persons with COVID-2019 cannot infect the virus to others when they don't have a fever

(COVID-19) virus spreads via respiratory droplets of infected individuals?

Isolation of people who are infected with the COVID-19 virus are effective to reduce the spread of the virus?

What is most sensitive test for Corona-virus?

What is most accurate test for (covid19)?

What is the mortality rate of COVID19?

What is transmission rout of Coronavirus (COVID 19)?

From where you get your information about (COVID-19)?

Knowledge score $($ mean $\pm S D)=0.81$ $\pm 0.15$

\section{Practice}

When doing normal hospital work wearing general medical masks to prevents infection by the (COVID-19) virus?

Do you wear general medical masks to prevent the infection by the COVID-19 virus?

It is not necessary for children and young adults to take measures to prevent the infection by the COVID-19 virus?

To prevent the infection by COVID-19, individuals should avoid going to crowded places such as bus stations and avoid taking busy public transportations?

People who have contact with someone infected with the COVID-19 virus should be immediately isolated in a proper place. In general, the observation period is 14 days?

In recent days, have you gone to any crowded place?

In recent days, have you worn a mask when leaving home?

Do you use hand sanitizer?

Do you use hand sensitizer after touching foreign surfaces outside your house?

Do you wash your hands with soap first thing when you get back home?

Do you use tissue paper when you sneeze or cough?

Do you still shake hands with people after spread of Coronavirus?

Do you still shake hands with people after Corona-virus pandemic? If yes how frequently?

Do you still hug people after spread of Corona-virus?

Do you take off your shoes once you get inside the house?

Practice score $($ mean $\pm S D)=0.78 \pm 0.2$

We used a rating scores to demonstrate the knowledge and practice which was from (100 - 90) excellent, $(89-80)$ very good, $(79-70)$ good, $(69-60)$ faire, $(59-50)$ borderline and below $(50 \%)$ fail. 
This study has found that medical students in Sudan demonstrated very good knowledge (88.9\%) and good practice $(78.6 \%)$ toward Covid19.

\section{Discussion}

With the emergence of COVID-19 from the city of Wuhan, China in $2019(1,2)$ and its rapid spread around the globe with more than 23000 cases in Sudan, more than 2.5 million case in Africa and more than 80 million cases around the globe until the end of December $2020(27,28)$, knowledge, awareness and practice (KAP) about COVID-19 among medical students is highly crucial. This study set out with the aim of assessing the knowledge and awareness and knowledge of medical students in Sudan concerning the novel corona virus COVID-19.

In this cross sectional study we provided an insight of knowledge and practice towards Covid-19 among medical students during the first wave of the pandemic. This study showed that the knowledge score among medical students in Sudan, was an overall good knowledge of (88.9\%), in addition about (78.6\%) of the participants had good practice. These findings are similar with that of Sonam Maheshwari (2019) in their study among medical students in the government medical college in Uttarakhan, India, which demonstrated good knowledge (92.7\%) and about (80\%) in the practice of the respondents, We attribute these good the source of information that medical students get about Covid-19 from social media being the most common source (74.7\%), news and TV (60.7\%), WHO updates (61.4\%), medical journals (29.3\%) and ministry of health updates (11\%.2). These sources are somehow similar to the results of Ahmad AlMohrej et.al which found that Social media was the commonest source (34\%) (22).

We found an interesting finding is that most of the students in level 2 identified the first initial symptom is headache followed by level $3,4,1,5$ and 6 respectively which was significantly different $(p<0,0016)$ Note level 6 students are less in number as mentioned above.

Overall there was no significant difference in Knowledge score between gender males and females. In the practice aspect females demonstrated better practice in using hands sanitizers, masks and not going to crowed places finally they think that Sudan can win the battle against Covid19.

We found a positive association between going to crowded places and age, with the age group 24-25 years having $75,5 \%$ of them not going to crowed places followed by $(18-20)$ age groups $(75.2 \%)$. While with other age groups showed good but less commitment.

\section{Conclusion}

This study has found that medical students in Sudan demonstrated good knowledge and good practice toward Covid19.

\section{Recommendations}


Although the results were very positive, further education and awareness should be carried out to increase the preparedness of medical students toward such pandemics and public health modules should focus more on the importance of the knowledge of newly emerging diseases and the practices towards them.

\section{References}

1. Phelan AL, Katz R, et al. The novel coronavirus originating in Wuhan, China: challenges for global health governance. JAMA., 2020

2. World Health Organization. Novel Coronavirus-China Disease Outbreak News. https://www.who.int/csr/don/12-january-2020-novel-coronavirus-china/en/.

3. Lu H, Stratton CW, Tang YW. Outbreak of pneumonia of unknown etiology in Wuhan, China: The mystery and the miracle. J Med Virol., 2020;92(4):401-2.

4. World Health Organization, WHO Director-General's Remarks at the Media Briefing on 2019-nCoV on 11 February 2020, (2020). https://www.who.int/dg/speeches/detail/who-director-general-s-remarksat-the-mediabriefing-on-2019-ncov-on-11february-2020.

5. Zhao X,Li J et al. Genomic characterization and epidemiology of 2019 novel coronavirus: implications for virus origins and receptor binding. Lancet. 2020; (published online Jan 29.https://doi.org/10.1016/S0140-6736(20)30251-8.)

6. Center of Disease Control (CDC) article: About 2019 Novel Coronavirus (2019-nCoV)

7. Q. Li, X. Guan, P. Wu, X. Wang, L. Zhou, Y. Tong, et al.Early transmission dynamics in wuhan, China, of novel coronavirus-infected pneumonia N. Engl. J. Med. (2020), 10.1056/NEJMoa2001316

8. W. Wang, J. Tang, F. Wei. Updated understanding of the outbreak of 2019 novel coronavirus (2019nCoV) in Wuhan, China J. Med. Virol., 92 (4) (2020), pp. 441-447, 10.1002/jmv.25689

9. World Health Organization (WHO): Coronavirus disease (COVID-2019) advice for the public. Available at: https://www.who.int/emergencies/diseases/novel-coronavirus-2019/advice-for-public 6. CDC Checklist:

10. C. Huang, Y. Wang, X. Li, L. Ren, J. Zhao, Y. Hu, et al.Clinical features of patients infected with 2019 novel coronavirus in Wuhan, China Lancet, 395 (10223) (2020), pp. 497-506, 10.1016/S01406736(20)30183-5

11. W.G. Carlos, C.S. Dela Cruz, B. Cao, S. Pasnick, S. JamilNovel wuhan (2019-nCoV) coronavirus

12. Am. J. Respir. Crit. Care Med., 201 (4) (2020), pp. 7-8, 10.1164/rccm.2014P7 J. Lei, J. Li, X. Li, X. QiCT imaging of the 2019 novel coronavirus (2019-nCoV) pneumoniaRadiology (2020), p. 200236, 10.1148/radiol.2020200236

13. A. Assiri, J.A. Al-Tawfiq, A.A. Al-Rabeeah, F.A. Al-Rabiah, S. Al-Hajjar, A. Al-Barrak, et al. Epidemiological, demographic, and clinical characteristics of 47 cases of Middle East respiratory syndrome coronavirus disease from Saudi Arabia: a descriptive studyLancet Infect. Dis., 13 (2013), pp. $752-761$ 
14. N. Lee, D. Hui, A. Wu, P. Chan, P. Cameron, G.M. Joynt, et al.A major outbreak of severe acute respiratory syndrome in Hong Kong N. Engl. J. Med., 348 (2003), pp. 1986-1994

15. L.T. Phan, T.V. Nguyen, Q.C. Luong, T.V. Nguyen, H.T. Nguyen, H.Q. Le, et al. Importation and humanto-human transmission of a novel coronavirus in Vietnam N. Engl. J. Med. (2020), 10.1056/NEJMc2001272

16. Fei Zhou, Ting Yu, et al. Clinical course and risk factors for mortality of adult inpatients with COVID19 in Wuhan, China: a retrospective cohort study. The lancet., 2020;395:1054-1062.

17. Wang D, Hu B, et al. Clinical Characteristics of 138 Hospitalized Patients With 2019 Novel Coronavirus-Infected Pneumonia in Wuhan, China. JAMA,. 2020; published online Feb 7. DOI: 10.1001/jama.2020.1585.

18. Zhibing Lu, Ming Chen, et al. Clinical Characteristics and Risk Factors for Fatal Outcome in Patients with 2019 -Coronavirus Infected Disease (COVID-19) in Wuhan, the lancet., 2020; DOI: http://dx.doi.org/10.2139/ssrn.3546069.

19. Deppermann C, Kubes P. Platelets and infection. Semin Immunol., 2016;28(6):536-545

20. Guan WJ, Ni ZY, et al. Clinical characteristics of 2019 novel coronavirus infection in China. N Engl J Med., 2020; DOI: https://doi.org/10.1101/2020.02.06.20020974.

21. Elisabeth Mahase,Covid-19: outbreak could last until spring 2021 and see 7.9 million hospitalised in the UK, BMJ.2020

22. Hamed Alzoubi, et al COVID-19 - Knowledge, Attitude and Practice among Medical and Non-Medical University Students in Jordan, journal of pure and applied microbiology, 14 (1) 2020

23. Bao-Liang Zhong, Knowledge, attitudes, and practices towards COVID-19 among Chinese residents during the rapid rise period of the COVID-19 outbreak: a quick online cross-sectional survey international journal of biological science; 16(10): 1745-1752, 2020

24. Ahmad Al-Mohrej,SajidaAgha Are Saudi medical students aware of middle east -respiratory syndrome coronavirus during an outbreak? journal of infection and public health, Volume 10, Issue 4, July-August 2017

25. General Office of the National Health Commission of the People's Republic of China. Guideline for the diagnosis and treatment of 2019 novel coronavirus (2019-nCoV) infected pneumonia (The Third Trial Version) 2020.

http://www.nhc.gov.cn/yzygj/s7653p/202001/f492c9153ea9437bb587ce2ffcbee1fa.shtml (access Feb 16, 2020)

26. National Health Commission of the People's Republic of China. A protocol for community prevention and control of the 2019 novel coronavirus (2019-nCoV) infected pneumonia (trial version) 2020. http://www.nhc.gov.cn/jkj/s3577/202001/dd1e502534004a8d88b6a10f329a3369.shtml (access Feb 16, 2020)

27. - CDC daily update-https://africacdc.org/covid-19/

28. - https://www.ecdc.europa.eu/en/geographical-distribution-2019-ncov-cases 
Figures

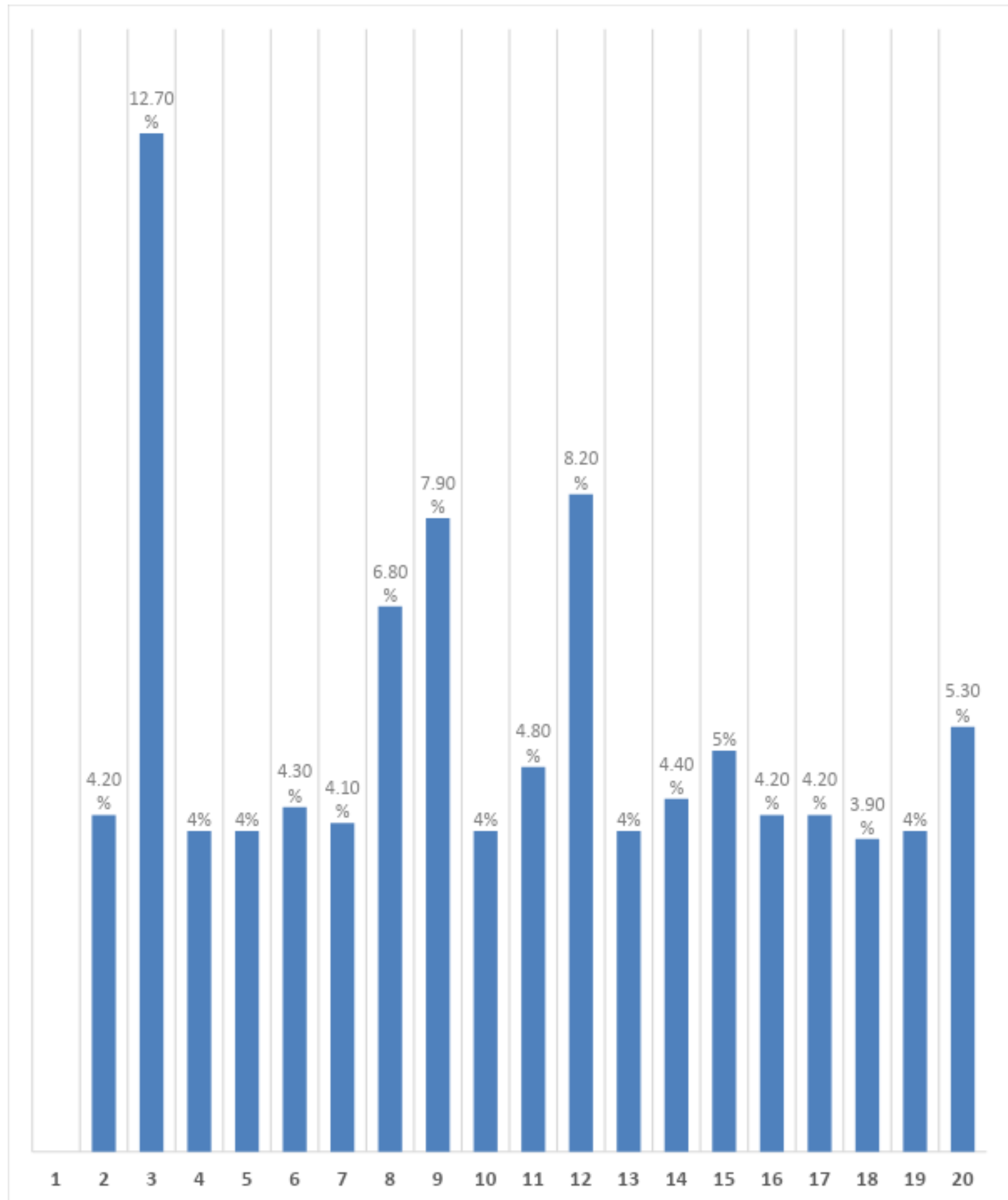

Figure 1

Number of questionnaires distributed in each university 


\section{age}

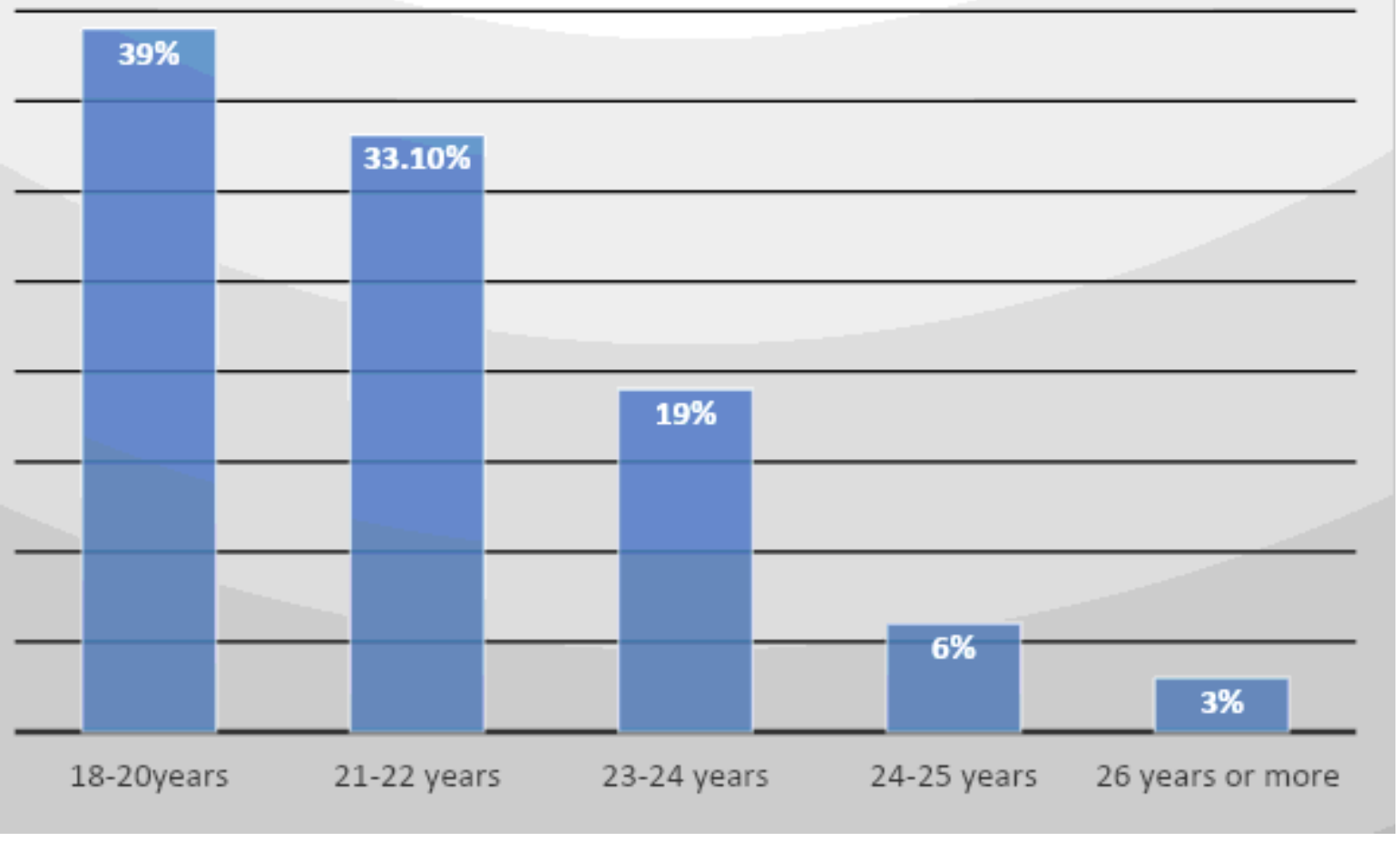

Figure 2

Age distribution of the participants 


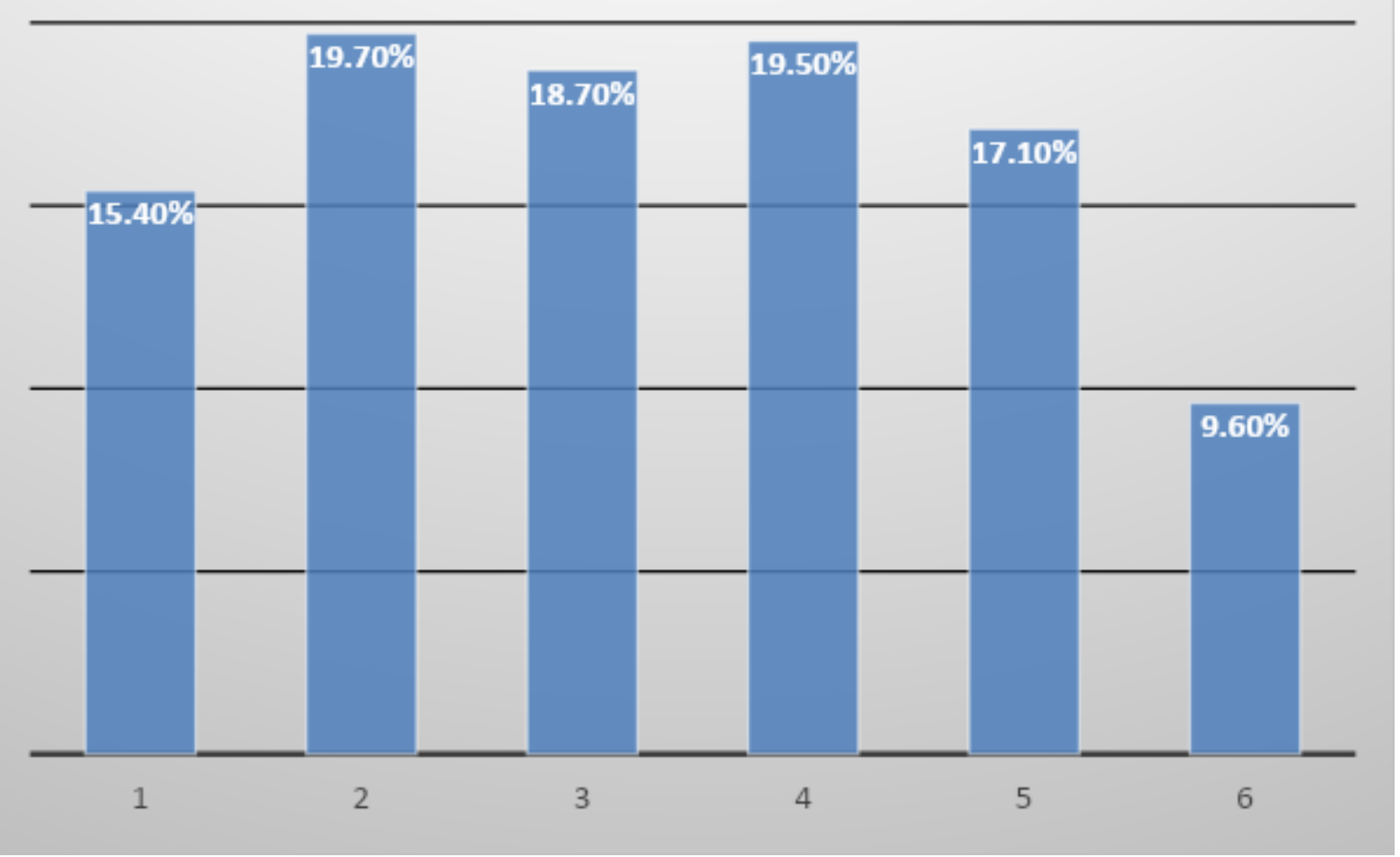

Figure 3

Participants level distribution

\section{Supplementary Files}

This is a list of supplementary files associated with this preprint. Click to download.

- AppendixStudyquestionnaire.docx 